\title{
Mass balance of the Lambert Glacier-Amery Ice Shelf system, East Antarctica: a comparison of computed balance fluxes and measured fluxes
}

\author{
Helen A. Frigker, ${ }^{1 *}$ Roland C. Warner, ${ }^{2}$ Ian Allison ${ }^{2}$ \\ ${ }^{1}$ Antarctic CRC and Institute of Antarctic and Southern Ocean Studies, University of Tasmania, Box 252-80, Hobart, Tasmania 7001, Australia \\ ${ }^{2}$ Antarctic CRC and Australian Antarctic Division, Box 252-80, Hobart, Tasmania 7001, Australia
}

\begin{abstract}
We combine European Remote-sensing Satellite (ERS-1) radar altimeter surface elevations (Fricker and others, 2000) with six different accumulation distributions to compute balance fluxes for the Lambert Glacier-Amery Ice Shelf drainage system. These interpolated balance fluxes are compared with fluxes derived from in situ measurements of ice thickness and velocity at 73 stations of the Lambert Glacier basin traverse and at 11 stations further downstream, to assess the system's state of balance. For the upstream line we obtain a range of imbalance estimates, from $-23.8 \%$ to $+19.9 \%$ of the observed flux, reflecting the sensitivity to the accumulation distributions. For some of the accumulation distributions the imbalance estimates vary significantly between different parts of the line. Imbalance estimates for the downstream line range from $-17.7 \%$ to $+70.2 \%$, with four of the estimates exceeding $+30 \%$, again reflecting the sensitivity of the result to input accumulation, and strongly suggesting that the mass balance of the region between the two lines is positive. Our results confirm the importance of accurate estimates of accumulation in icesheet mass-balance studies. Furthermore, they suggest that it is not possible to accurately determine the state of balance of large Antarctic drainage basins on the basis of currently available accumulation distributions.
\end{abstract}

\section{INTRODUGTION}

The mass balance of the Antarctic ice sheet is an important climatic variable since any significant deviation from a balanced state directly influences global sea level (Meier, 1993). However, an accurate assessment of this balance is nontrivial because the ice sheet is so vast and in situ measurements are sparse, and because the time-scales of the input and output terms are so different. Insufficient knowledge of the surface velocity factor (i.e. the ratio of the surface velocity to columnaveraged velocity) adds to the complexity of the task. Despite these difficulties, many authors have made estimates of the mass balance of the entire ice sheet from observations (e.g. Bentley and Giovinetto, 1991; Jacobs and others, 1992). Others have restricted their studies to individual drainage systems (e.g. Shimizu and others, 1978; Whillans and Bindschadler, 1988), providing useful information on the response of these drainage systems to any regional changes in climate.

Satellite-radar altimeters have recently provided glaciologists with digital elevation models (DEMs) unprecedented in terms of spatial extent and accuracy. Using this high-quality surface topographic information, the spatial distribution of the theoretical ice flux that would locally balance a given

\footnotetext{
* née Phillips; now at Institute of Geophysics and Planetary Physics, Scripps Institution of Oceanography, University of California, San Diego, 9500 Gilman Drive, La Jolla, California 92093-0225, U.S.A.
}

accumulation distribution (the "balance" flux) can be computed (Budd and Warner, 1996). Comparison of the computed flux with "observed" flux at specific locations derived from in situ measurements leads to an assessment of the state of balance. Here we summarize the results of a comparison of computed balance fluxes and observed fluxes for the Lambert Glacier-Amery Ice Shelf system (hereafter referred to as the "Lambert-Amery system"), using a $5 \mathrm{~km}$ DEM derived from European Remote-sensing Satellite (ERS-1) radar altimeter data (Fricker and others, 2000) and six different accumulation distributions for the region. This provides an assessment of the sensitivity of the balance-flux computation to the input accumulation distribution and also a new estimate of the state of balance of the Lambert-Amery system.

The Lambert-Amery system, located at $68.5-81^{\circ} \mathrm{S}, 40-$ $95^{\circ} \mathrm{E}$, is the largest glacier-ice-shelf system in East Antarctica (Fig. 1). It is defined here as: that portion of the Antarctic ice sheet containing ice that drains through the front of the Amery Ice Shelf. The total area of the Lambert-Amery system is $1550000 \mathrm{~km}^{2}$, which includes $69000 \mathrm{~km}^{2}$ of floating ice in the Amery Ice Shelf (Phillips, 1999). The grounded portion of the Lambert-Amery system thus covers $16 \%$ of the grounded East Antarctic ice sheet $\left(9245000 \mathrm{~km}^{2}\right.$; Drewry and others, 1982) and is an important drainage basin in terms of the overall mass balance of Antarctica. This large system has a highly convergent flow pattern, with the total mass outflux focused through the front of the Amery Ice Shelf which accounts for only about $2.5 \%$ of the total East Antarctic coastline. 


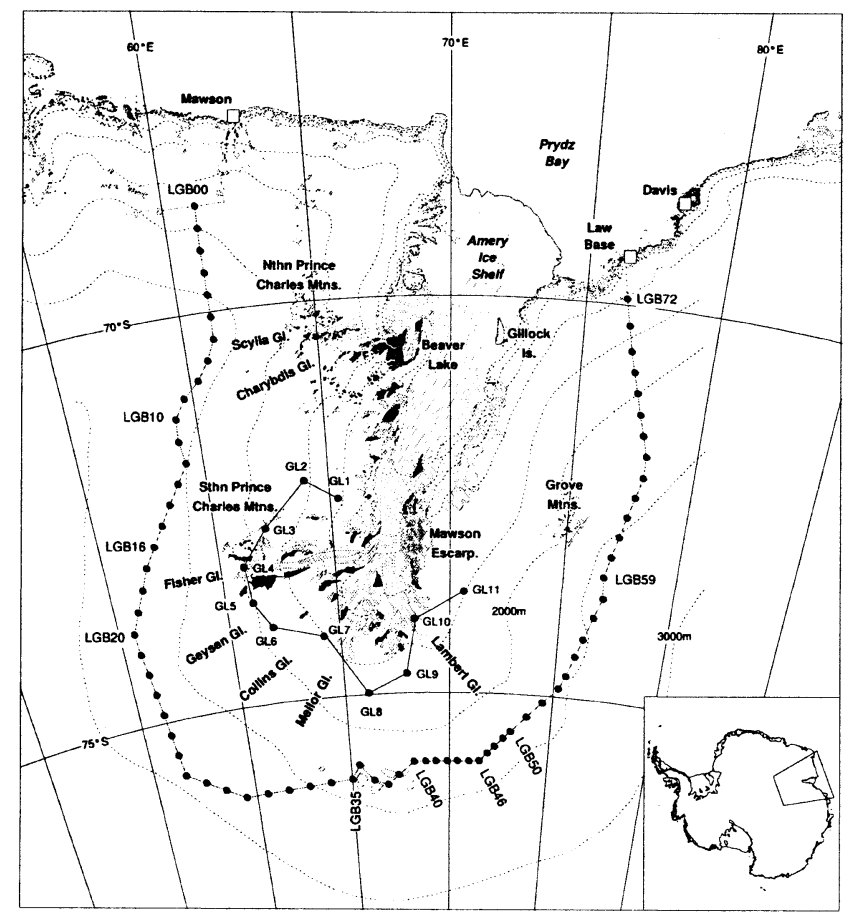

Fig. 1. Map of the Lambert-Amery system, showing the location of the LGB and GL sites used in this study.

\section{PREVIOUS MASS-BALANCE STUDIES OF THE LAMBERT-AMERY SYSTEM}

Allison (1979) estimated the mass balance of the Lambert Glacier drainage basin (LGDB) from survey data. The LGDB is enclosed entirely within the Lambert-Amery system, and is the part of the system that drains through the major ice streams entering the rear of the Amery Ice Shelf (see Fig. 1). It does not include any ice that originates from the parts of the Lambert-Amery system at the west or east margins of the Amery Ice Shelf. Allison (1979) estimated mass fluxes for the LGDB, obtaining a total net accumulation of $60 \mathrm{Gt} \mathrm{a}^{-1}$ for the interior of the basin upstream of the $\mathrm{GL}^{*}$ line (equivalent to an average net accumulation over the basin of $55 \mathrm{~kg} \mathrm{~m}^{-2} \mathrm{a}^{-1}$ ), and a discharge across the GL line into the major ice streams at the rear of the Amery Ice Shelf of 29.7 $\mathrm{Gt} \mathrm{a}^{-1}$. This yielded an overall positive imbalance for the interior of approximately $30 \mathrm{Gt} \mathrm{a}^{-1}$. Allison (1979) called the system of ice streams converging into the Amery Ice Shelf the "Lambert Glacier System". Mass losses within this part of the LGDB were estimated at $18 \mathrm{Gta}^{-1}\left(7 \mathrm{Gta}^{-1}\right.$ through net ablation and $11 \mathrm{Gta}^{-1}$ via outflow into the Amery Ice Shelf), yielding a positive mass balance of $12 \mathrm{Gt} \mathrm{a}^{-1}$.

Bentley and Giovinetto (1991) estimated the imbalance of several drainage basins, including the Lambert-Amery system, as part of continent-wide studies. Surface mass input data had previously been assembled by Giovinetto and Bentley (1985) using data from the 1968-70 Australian National Antarctic Research Expeditions (ANARE) surveys (Budd and others, 1982) and McIntyre's (1985) reinterpretation of surface accumulation based on satellite imagery. For the 1991 study, McIntyre's (1985) surface mass input data were slightly modified to allow for Allison's (1979) original interpretation of a

* The GL line is a hypothetical line that connects Allison's (1979) sites GL1-11.

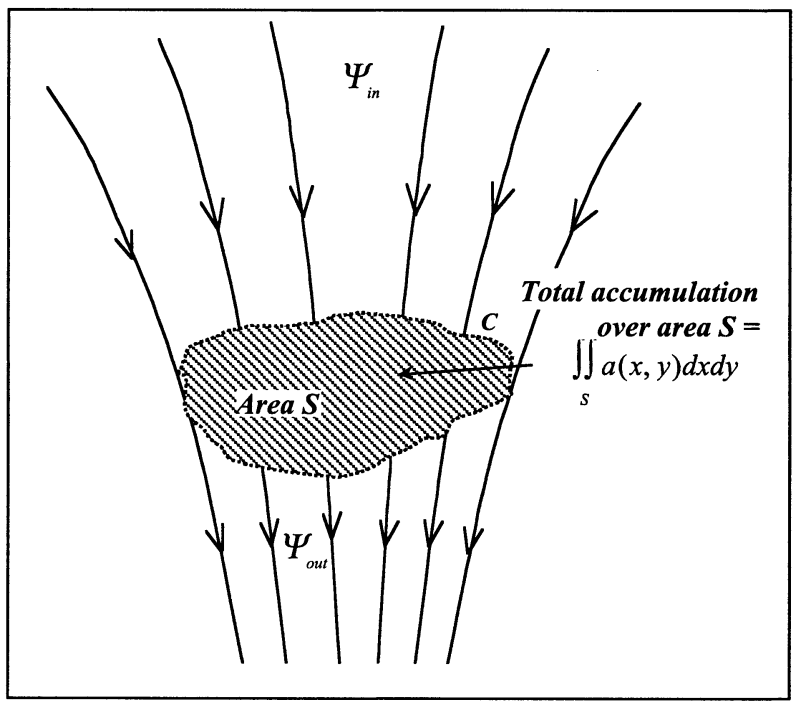

Fig. 2. Simple schematic diagram to illustrate the balance-flux concept. The total mass flux leaving the closed area $S$ is equal to the sum entering it, plus the integrated accumulation over $S$.

positive accumulation rate over an extensive region in the interior. For the grounded ice, Bentley and Giovinetto (1991) obtained a positive mass imbalance of $39 \mathrm{Gta}^{-1}(78 \%$ of total net accumulation) for the entire LGDB. This compares with an imbalance of $42 \mathrm{Gta}^{-1}$ for the LGDB $\left(30 \mathrm{Gta}^{-1}\right.$ for the interior plus $12 \mathrm{Gta}^{-1}$ for the Lambert Glacier System) obtained by Allison (1979).

\section{BALANCE FLUXES}

The "balance-flux" distribution of a glacier system is the hypothetical distribution of mass flux that would exist if the system were in "steady state". It can be calculated from knowledge of the surface slopes (to define the flow direction), combined with the spatial distribution of the mass accumulation rate (the "accumulation distribution"). When compared with fluxes derived from in situ velocity and thickness measurements, balance-flux distributions provide local information on the state of balance, allowing more detailed studies beyond simple summation of the accumulation over entire drainage basins. A computed balance-flux distribution for Wilkes Land was presented by Budd and others (1971), and the value of accurate surface elevation information is demonstrated in Budd and Warner (1996) and in the present paper. As the algorithm used in the present work differs in several respects from those sketched in Budd and Warner (1996), it is appropriate to present some details here.

Consider a glacier system defined over a horizontal $(x, y)$ domain. The basic "balance" assumption is that the mass of ice flowing out of any area $S$ within the domain $\left(\Psi_{\text {out }}\right)$ exactly equals the sum of the inflow $\left(\Psi_{\text {in }}\right)$ and the ice accumulated over the area $S$ (see Fig. 2), with the geometry (ice thickness and surface elevation) of the system remaining constant. In terms of the areal integral of the net surface accumulation $a(x, y)$ over $S$ :

$$
\Psi_{\text {out }}=\Psi_{\text {in }}+\iint_{S} a(x, y) \mathrm{d} x \mathrm{~d} y .
$$

In such a steady state the integrated accumulation over the 
region $S$ is also exactly matched by the net volume of ice that flows across $C$, the boundary of $S$ :

$$
\int_{C} \underline{V}(l) Z(l) \cdot \underline{\hat{n}} \mathrm{~d} l=\iint_{S} a(x, y) \mathrm{d} x \mathrm{~d} y,
$$

where $\underline{\hat{n}}$ is the unit outward normal to the curve $C, \underline{V}$ is the column-averaged velocity vector (the balance velocity) and $Z$ is the ice thickness. The quantity $\underline{V} Z$ in Equation (2) is a continuous vector field $\underline{\Phi}_{\mathrm{B}}(x, y)$ referred to as the "balanceflux" distribution, i.e.

$$
\underline{\Phi}_{\mathrm{B}}(x, y)=\underline{V}(x, y) Z(x, y) .
$$

The calculations use two sets of input data (on the same grid): a DEM and an accumulation distribution. The direction of ice flow is derived from the DEM by assuming that the ice flow follows the surface slope. Budd (1968) showed that this holds if the surface slope is averaged on a horizontal scale of 10-20 ice thicknesses. Accordingly, to satisfy this condition the DEM should be smoothed over an appropriate horizontal scale.

Finding the balance-flux distribution then involves solving the set of equations obtained by applying Equation (2) to each gridcell, making use of the prescribed ice-flow directions. This set of equations couples together the flux magnitudes of neighbouring cells. Budd and Warner (1996) indicated how to avoid the complication of directly solving this coupled linear system, while at the same time incorporating efficiently the flow-direction information from the DEM, by working progressively from higher to lower elevations.

This scheme produces a balance-flux distribution for the entire grid (magnitude, $\left|\Phi_{\mathrm{B}}\right|$, and flow direction), as well as the individual components of the balance-flux vector field, $\Phi_{x}$ and $\Phi_{y}$ on "staggered" grids.

The balance-flux algorithm uses a scalar quantity: the outflow rate of ice from a gridcell $\left(\Psi_{i, j}^{\text {out }}\right)$. Here, in contrast to some of the schemes suggested in Budd and Warner (1996), a "centred-difference" scheme is used, with an individual gridcell, cell $l_{i, j}$ having exactly four neighbours (cell ${ }_{i-1, j}$, $\operatorname{cell}_{i+1, j}, \operatorname{cell}_{i, j-1}$ and $\left.\operatorname{cell}_{i, j+1}\right)$.

Separating the boundary flux integral around each gridcell into inflow and outflow from these neighbours (an individual cell edge can only have inflow or outflow across it), Equation (1) for the $\operatorname{cell}_{i, j}$ becomes:

$$
\Psi_{i, j}^{\text {out }}=a_{i, j} l^{2}+\Psi_{i, j}^{\text {in }},
$$

where $l$ is the cell size ( $5 \mathrm{~km}$ in the present study).

The slope (and flow) direction is incorporated by apportioning the outflow $\left(\Psi_{i, j}^{\text {out }}\right)$ from a gridcell between those neighbours that lie downslope, by dividing the total outflow from $\operatorname{cell}_{i, j}$ in proportion to the elevation differences. For example, the contributing flow from $\operatorname{cell}_{i, j}$ to $\operatorname{cell}_{i, j+1}$ is:

$$
\frac{h_{i, j}-h_{i, j+1}}{N} \Psi_{i, j}^{\text {out }}
$$

where $h_{i, j}$ is the surface elevation in $\operatorname{cell}_{i, j}$ and $N$ is a normalization factor to ensure that the outflow contributions from cell $_{i, j}$ sum to $\Psi_{i, j}^{\text {out }}$. For each gridcell, the total scalar inflow of ice is the sum of the outflowing contributions from neighbouring upslope cells.

The cell outflow rates can be found sequentially by sorting the cells by elevation and proceeding downslope. At each stage the total flow into the present gridcell is already known from the contributions of all points upslope, which have already been computed using Equations (4) and (5). This procedure yields the scalar flow field $\Psi_{i, j}^{\text {out }}$, i.e. a field of the outflow at each gridcell.
The field $\Psi_{i, j}^{\text {out }}$ is not a direct measure of the flux magnitude (this distinction was not made clear in Budd and Warner (1996)), since the rate of ice flow through a cell with side length $l$ is related to both the flux magnitude and the direction of flow through the cell. If the angle of the flow direction relative to the grid orientation is denoted by $\theta$, then, taking the outflow from a cell as a good approximation to the flow through it, the flux magnitude $\left(\Phi_{\mathrm{B}}=\left|\underline{\Phi}_{\mathrm{B}}\right|\right)$ is obtained from $\Psi_{i, j}^{\text {out }}$ by:

$$
\Phi_{\mathrm{B}}=\frac{\Psi_{i, j}^{\text {out }}}{l(|\cos \theta|+|\sin \theta|)} .
$$

Simultaneously with the calculation of $\Psi_{i, j}^{\text {out }}$, separate $x$ and $y$-component fluxes $\left(\Phi_{x}\right.$ and $\left.\Phi_{y}\right)$ are calculated on "staggered" grids. These flux components are defined on the corresponding links between gridpoints, and are simply obtained by taking the apportioned outflow across the relevant cell boundary crossed by the link, and dividing by the cell edge length $l$. Each link is encountered at most once during the progression down the elevations of the ice sheet.

\section{COMPUTATION OF BALANGE FLUXES AND OBSERVED FLUXES FOR LAMBERT-AMERY SYSTEM: DATASETS AND METHOD}

\subsection{Elevation dataset}

A $5 \mathrm{~km}$ resolution DEM of the Lambert-Amery system (LAS-DEM), generated using ERS-1 satellite radar altimetry as described in Fricker and others (2000), provides the topographic information for this study. The differences between the measured elevations at the 73 Lambert Glacier traverse stations and the corresponding LAS-DEM elevations have a mean of $12.2 \mathrm{~m}$ (LAS-DEM height minus station height) and an $\mathrm{rms}$ of $14.8 \mathrm{~m}$.

Preparation of the LAS-DEM involved a number of preliminary steps. The LAS-DEM was first smoothed on a horizontal scale of $35 \mathrm{~km}$ using a simple, "moving-area" averaging scheme, where each cell was assigned the average value of itself and 48 surrounding cells. The aim of this was to maintain the $5 \mathrm{~km}$ spatial resolution of the LAS-DEM while incorporating the slope information at a scale more appropriate to ice flow. Experiments were also carried out with a smoothing scale of $15 \mathrm{~km}$, but Phillips (1999) found that the $35 \mathrm{~km}$ scale gave a more coherent picture of the flow.

In regions of positive accumulation, an ice sheet in steady state can have no surface hollows or exactly flat regions, if it is assumed that ice flow follows the surface slope. The next data-preparation step, which ensures that there are no such occurrences in the DEM, is referred to as elevation "polishing". The DEM is checked for local hollows and zero-gradient regions. Local hollows in the DEM are filled in, so that no site is a local minimum. Slight slopes are created for any flat spots by adding a small random amount to the appropriate elevation.

\subsection{Accumulation datasets}

Almost all of the precipitation that falls on the Antarctic ice sheet becomes ice. The net surface mass balance, often referred to as net accumulation, includes all processes by which mass is gained or lost to the ice-sheet surface, i.e. precipitation, evaporation, melting and run-off, wind redistribution, surface hoar deposition. 
Many attempts have been made to compile maps of the distribution of annual accumulation for Antarctica, from interpolations of the limited observational data and from a variety of techniques using atmospheric model results. In this study we use six accumulation distributions representing each of these broad types; these are summarized in Table 1.

The accumulation distributions designated 82-OBS, 97OBS and 99-OBS are published compilations which are all based on in situ observations at accumulation stakes and from ice-pit and ice-core stratigraphy. Each compilation considers all the data available at the time of preparation, so the three distributions involve considerable common data, especially from earlier sources. The data are of varying accuracy, and due to their collection dates and their methods they represent observational epochs at different times and of varying duration. The 82-OBS compilation (Budd and Smith, 1982) covers the whole continent and uses data available up to 1980. 82-OBS includes very few data from the interior of the Lambert Glacier basin above $1500 \mathrm{~m}$ surface elevation. The distributions 97-OBS (Higham and others, 1997) and 99-OBS (Vaughan and others, 1999) include more recent data, including 1989-95 measurements at approximately 1000 bamboo canes around the Lambert Glacier basin (LGB) traverse route (Higham and Craven, 1997; measurements on the eastern side of the basin cover only the last year of this period). The 97-OBS distribution is only defined for the Lambert-Amery system, whereas 99-OBS is defined for the whole continent.

The three remaining accumulation distributions are derived from three different types of atmospheric models. Global climate models (GCMs) and numerical weather-forecasting models (the latter used for both data assimilation and prediction) can provide estimates of moisture transport, precipitation and evaporation that can be used to derive the broad-scale distribution of accumulation over Antarctica. These models typically have a resolution of several hundred kilometres and cannot account for local topographic effects or wind redistribution of snow. The distribution designated GASP (Budd and others, 1995) is based on moisture advection computations using global atmospheric observations synthesized in the Australian Bureau of Meteorology (BoM) Global Atmospheric Assimilation and Prediction Scheme (GASP). Moisture-transport fluxes and their divergences are computed using the total atmospheric columnar water content and wind speeds derived from these analyses for the epoch 1989-92. The net flux divergence yields the difference between the precipitation and the evaporation, which approximates the net accumulation.
Precipitation and evaporation fields can also be obtained directly from numerical weather-prediction models. The European Centre for Medium-range Weather Forecasting (ECMWF) model has been rerun for the years 1979-93 (assimilating the corresponding global observational data), and the resultant precipitation and evaporation fields are available (as "ECMWF Re-analysis Sample Data" at $2.5^{\circ}$ by $2.5^{\circ}$ resolution) on CD-ROM (ECMWF, 1997). An accumulation distribution for Antarctica is obtained by subtracting the evaporation field from the precipitation field $(p-e)$ and is designated ECMWF.

Estimates of annual precipitation and evaporation can also be obtained from GCM simulations. A recent high-resolution $\left(2^{\circ}\right.$ by $\left.2^{\circ}\right)$ Commonwealth Scientific and Industrial Research Organisation (CSIRO) GCM run (T63) for the period 1950-91, constrained by historical sea-surface temperatures, has provided a model accumulation distribution that is comparable with observations (Smith and others, 1998). The accumulation distribution designated CSIRO is derived from the 1981-90 portion of that simulation.

These six different distributions of net annual accumulation were used as input to the balance-flux algorithm in this study of the Lambert-Amery system.

\subsection{Measured surface ice velocity, ice thickness and flux}

The ANARE LGB traverse program took place over five austral summers between 1989/90 and 1994/95. The traverse route between Mawson and Davis stations approximately followed the $2500 \mathrm{~m}$ surface elevation contour for $2200 \mathrm{~km}$ around the interior of the LGDB (Fig. 1). Seventy-three icemovement stations (LGB00-LGB72) were established at approximately $30 \mathrm{~km}$ spacing along most of the LGB traverse route, and at $15 \mathrm{~km}$ spacing across the major streams (Kiernan, in press). At each station, surface ice-flow velocity magnitude and azimuth were derived from static global positioning system (GPS) observations made in at least two separate years. All but one of these ice-velocity determinations had an estimated accuracy of better than $1 \mathrm{~m} \mathrm{a}^{-1}$, and about $60 \%$ had an estimated accuracy better than $0.3 \mathrm{~m} \mathrm{a}^{-1}$ (Kiernan, in press). Digitally recorded ice-thickness soundings were made approxi-mately every $10 \mathrm{~m}$ along the route with a $100 \mathrm{MHz}$ ice-radar system (Higham and others, 1995; Craven and others, in press) and averaged over $1 \mathrm{~km}$ sections. The resolution of the individual soundings is about $20 \mathrm{~m}$, although in some short sections where no bottom echo was obtained, the radio-echo sounding (RES) measurements were interpolated with gravity data.

Table 1. Summary of the six accumulation distributions used in this study, including a brief description of how they were compiled and the epochs they represent

82-OBS Compilation of all available in situ data (repeated cane measurements Observations covering different time Budd and Smith (1982) and snow-pit and core stratigraphy). Continent-wide compilation intervals within the period $1957-80$

97-OBS As for 82-OBS, but including extensive new data (1989-95) from LGB traverse. Lambert-Amery System only As for 82-OBS, for 1957-95

Higham and others (1997)

99-OBS As for 97-OBS. Continent-wide compilation

GASP Moisture-advection computation from global atmospheric analyses synthesized in GASP numerical weather-forecasting model

ECMWF Direct $p-e$ fields from ECMWF model re-analyses

As for 97-OBS, for 1957-97 1989-92

1979-93

CSIRO $\quad p-e$ fields from CSIRO GCM
$1981-90$
Vaughan and others (1999)

Budd and others (1995)

P. Reid (personal communication, 1998)

Smith and others (1998) 
Earlier in situ measurements of ice velocity and thickness are also available further downstream in the basin, from the 11 sites (GL1-GL11) used in mass-balance estimates by Allison (1979). These locations, 50-100 km apart, defined the perimeter of the Lambert Glacier system used in that study and were chosen to give a representative sample of the ice flow into the Lambert Glacier system, three of the stations being placed upstream of each of the three major ice streams (Allison, 1979).

For each segment of the LGB traverse the "observed" flux was derived from the traverse data. The component of the observed flux orthogonal to the line between adjacent stations was calculated in Cartesian coordinates on a polar stereographic projection using simple vector geometry. It is assumed that each segment is adequately represented by an average ice-thickness value and velocity components which are simple averages of the $u$ and $v$ components at the LGB stations at either end of that segment. The resultant surface measured velocity vector is then $\mathbf{V}=u \mathbf{i}+v \mathbf{j}$.

The observed flux vector $\left(\underline{\Phi}_{0}\right)$ through each segment is:

$$
\underline{\Phi}_{\mathrm{o}}=0.87 * \underline{V}_{\mathrm{s}} * L * \bar{Z},
$$

where $L$ is the length of the segment (in $\mathrm{km}$ ) and 0.87 is the surface velocity factor, i.e. the ratio of the depth-averaged column velocity $(V)$ to the surface velocity $\left(V_{\mathrm{s}}\right)$, which allows for the fact that velocity decreases with depth. The value of 0.87 used here for the surface velocity factor is that used by Budd and Warner (1996). This quantity is not accurately known, as it depends on ice rheology, ice temperature profiles and the possible presence of basal sliding. Budd and others (1971) give a range of 0.85-0.92, moving from the interior towards the coast in Wilkes Land, while Hamley and others (1985) found a value of 0.89 by assuming a state of balance in their comparison of observed and balance fluxes in the same area. As measurements of velocity and ice thickness improve, this factor becomes a major source of present uncertainty (a few per cent) in $\underline{\Phi}_{0}$. The component of $\underline{\Phi}_{0}$ orthogonal to the line segment is calculated from the scalar product of $\underline{\Phi}_{0}$ with the unit normal to the traverse line. The unit normal is derived from the equation of the line segment, defined by the difference in coordinates of the stations at each end.

\section{RESULTS OF BALANGE-FLUX GALGULATIONS}

Balance fluxes were calculated for the Lambert-Amery system using the LAS-DEM smoothed at the $35 \mathrm{~km}$ scale and the six accumulation distributions discussed above. The balance-flux distribution for the whole system is presented first, then balance fluxes and measured fluxes are compared at the LGB traverse stations and the GL stations further downstream.

\subsection{Balance-flux distribution for the Lambert-Amery system}

The $35 \mathrm{~km}$ smoothing scale is an appropriate one (approximately ten ice thicknesses) for averaging slope information for ice-flow studies in this region. As an example, the balance-flux distribution derived from the 99-OBS accumulation dataset is shown in Figure 3. The plot provides a powerful representation of the pattern of surface ice flow that would exist if the system were in balance. Streaming behaviour of the flow in topographic channels, such as the Lambert Glacier graben, can be clearly seen. The locations of the major streams

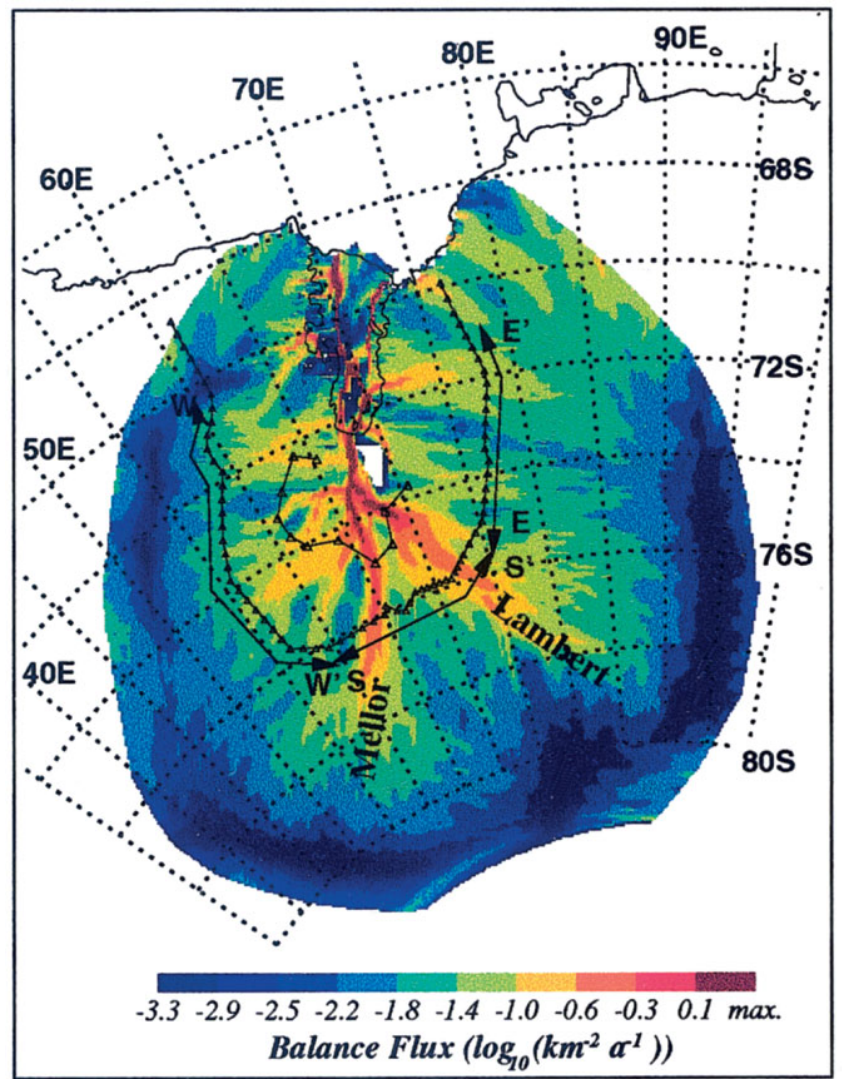

Fig. 3. Distribution of balance flux ( $\log _{10}$ scale) for Lambert-
Amery system calculated from the 99-OBS accumulation
distribution and the $35 \mathrm{~km}$ smoothed LAS-DEM. The location
of the LGB traverse and GL sites used in this study are shown.
Segments of the LGB traverse marked $W-W^{\prime}, S-S^{\prime}$ and $E-E^{\prime}$
correspond to the West, Streams and East segments, respectively
(Figs 4 and 6). The locations of the streams that become
Lambert and Mellor Glaciers are marked accordingly. The
white region east of the confluence of the major streams in the
basin indicates the Mawson Escarpment where (on the scale
used here) the ice fluxes are negligible.

that become Lambert and Mellor Glaciers are labelled. In these regions, the flux increases by an order of magnitude. The plot is presented using a logarithmic scale because of the large range of flux magnitudes encountered with such strong convergence of the flow into major streams in the basin.

\subsection{Comparison of balance fluxes with observed fluxes from LGB traverse}

The orthogonal components of the observed flux vector orthogonal to the line segment were calculated (as described in section 4.3) for each of the 72 line segments between the 73 LGB stations. For each of the six balance-flux distributions the corresponding components of the balance flux for each line segment were interpolated from the staggered flux grids $\left(\Phi_{x}\right.$ and $\left.\Phi_{y}\right)$ using a bilinear interpolation scheme. They were then used to construct the balance-flux vector for the midpoint of each segment. The component of this vector orthogonal to the segment was calculated by taking the scalar product of the balance-flux vector at the midpoint of each sector with the unit normal to the traverse line. The resulting orthogonal components of the observed and balance fluxes through each of the LGB segments are plotted in Figure 4.

The ice streams corresponding to maxima in these fluxes can be seen clearly in Figure 4. Note that in each plot the 

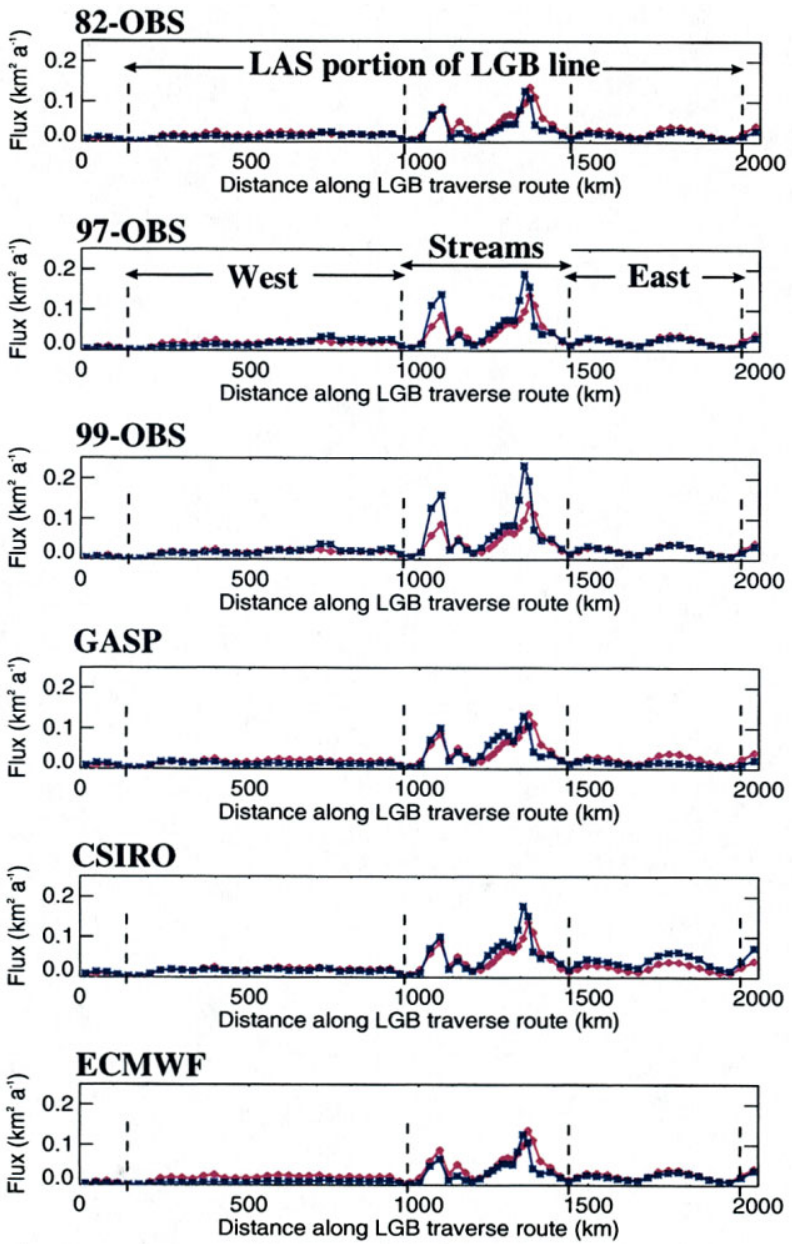

Fig. 4. Orthogonal components of observed fluxes (red) and balance fluxes (blue) for the six accumulation distributions for each segment of the LGB traverse.

observed and computed maxima are closely matched in location, although the magnitudes vary. This is because the total flux is apportioned using the surface slopes from the (smoothed) LAS-DEM. The differing flux magnitudes arise from the differences between the accumulation distributions in the catchment of each segment. Note also that for each stream the balance-flux maximum is often higher than the observed flux maximum. This results from the sampling density $(15 \mathrm{~km})$ of the measurements across the streams, meaning that there is not necessarily a measurement made at the flux maximum.

Flowlines derived from the LAS-DEM show that ice flowing between stations LGB05 and LGB69 drains through the front of the Amery Ice Shelf (Phillips, 1999). The total integrated flux between these stations is an estimate of the total flux across the LGB traverse line that is part of the Lambert-Amery system. This number, when compared to the total integrated balance flux between the same stations, gives an idea of the state of balance of the higher-elevation part of the Lambert-Amery system.

The measurements along the LGB traverse line were used to derive a total volume flux (in $\mathrm{km}^{3} \mathrm{a}^{-1}$ ), which was converted into a mass flux (in $\mathrm{Gt} \mathrm{a}^{-1}$ ) by multiplying by an average ice density of $910 \mathrm{~kg} \mathrm{~m}^{-3}$. The total integrated mass flux orthogonal to the LGB line derived from the observations between LGB05 and LGB69 was $44 \mathrm{Gta}^{-1}$. The total integrated balance flux orthogonal to the same part of the LGB line was calculated for each net accumulation distribution, and the percentage mass "imbalance" was cal-
Table 2. Integrated orthogonal component of the observed flux across various sections of the Lambert-Amery portion of the LGB line (East, West, Streams and Total), together with imbalance ratios for each section (excess of the integrated balance flux above the observed flux as a percentage of the observed flux), derived from the six accumulation distributions

\begin{tabular}{|c|c|c|c|c|}
\hline & West & Streams & East & Total \\
\hline & \multicolumn{4}{|c|}{ Observed flux $\left(\mathrm{Gt} \mathrm{a}^{-1}\right)$} \\
\hline & 13.6 & 21.8 & 8.6 & 44.0 \\
\hline & \multicolumn{4}{|c|}{ Imbalance $(\%)$} \\
\hline 82-OBS & -21.4 & -23.9 & -27.5 & -23.8 \\
\hline 97-OBS & -4.8 & +19.7 & -10.6 & +6.2 \\
\hline 99-OBS & +3.8 & +39.3 & -3.7 & +19.9 \\
\hline GASP & -29.1 & +3.1 & -48.0 & -16.8 \\
\hline CSIRO & -14.1 & +20.4 & +70.8 & +19.5 \\
\hline ECMWF & -62.3 & -25.2 & -15.0 & -34.7 \\
\hline
\end{tabular}

culated (Table 2; last column). This is the difference between the total balance flux and the observed flux as a percentage of the total observed flux. Negative percentage values refer to negative mass balances (i.e. the observed fluxes are larger than the computed balance fluxes), whilst positive values refer to positive mass balances. The imbalance estimates from the six accumulation distributions vary widely, from $-34.7 \%$ (ECMWF) to $+19.9 \%$ (99-OBS).

\subsection{Comparison of balance fluxes across the GL perimeter}

Downstream of the LGB line, the six balance-flux distributions were interpolated at 30 points in between each of the GL stations, corresponding to a spacing of $1-3 \mathrm{~km}$. An observed "spot" flux magnitude was obtained for each GL station from the product of the measured surface velocity, the ice thickness and a surface velocity factor of 0.87 . Figure 5 illustrates the interpolated balance-flux magnitudes, together with these "spot" observed fluxes.

As discussed earlier, the mass flux across the GL line into the Lambert Glacier system has been estimated by Allison (1979) from field observations that included aerial RES data (Morgan and Budd, 1975) and surface velocity measurements at the GL stations. Allison (1979) interpolated surface velocities between the GL stations with reference to the ice thickness, and used flowlines on satellite imagery to define the boundaries of fast-moving ice streams. The normal velocity and the thickness distributions were integrated to derive a total mass flux across the line of $29.7 \mathrm{Gta}^{-1}$ (Allison, 1979), assuming a surface velocity factor of 0.8 and a column-averaged ice density of $0.87 \mathrm{Mg} \mathrm{m}^{-3}$. This estimate, which converts to $33.8 \mathrm{Gt} \mathrm{a}^{-1}$ for the surface velocity factor and ice density used in the present study, lies within the range of estimates derived from the six different balance-flux distributions. In a similar manner to that described for the LGB line, the total integrated balance flux across the GL line was computed for each distribution. The resulting imbalance values, as a percentage of the integrated observed flux, are shown in the top right corner of each of the plots in Figure 5. They range from $-17.7 \%$ (ECMWF) to $+70.2 \%$ (99-OBS). However, four of the values are greater than $+30 \%$, strongly suggesting that the mass balance of the Lambert-Amery system south of the GL line is positive. 

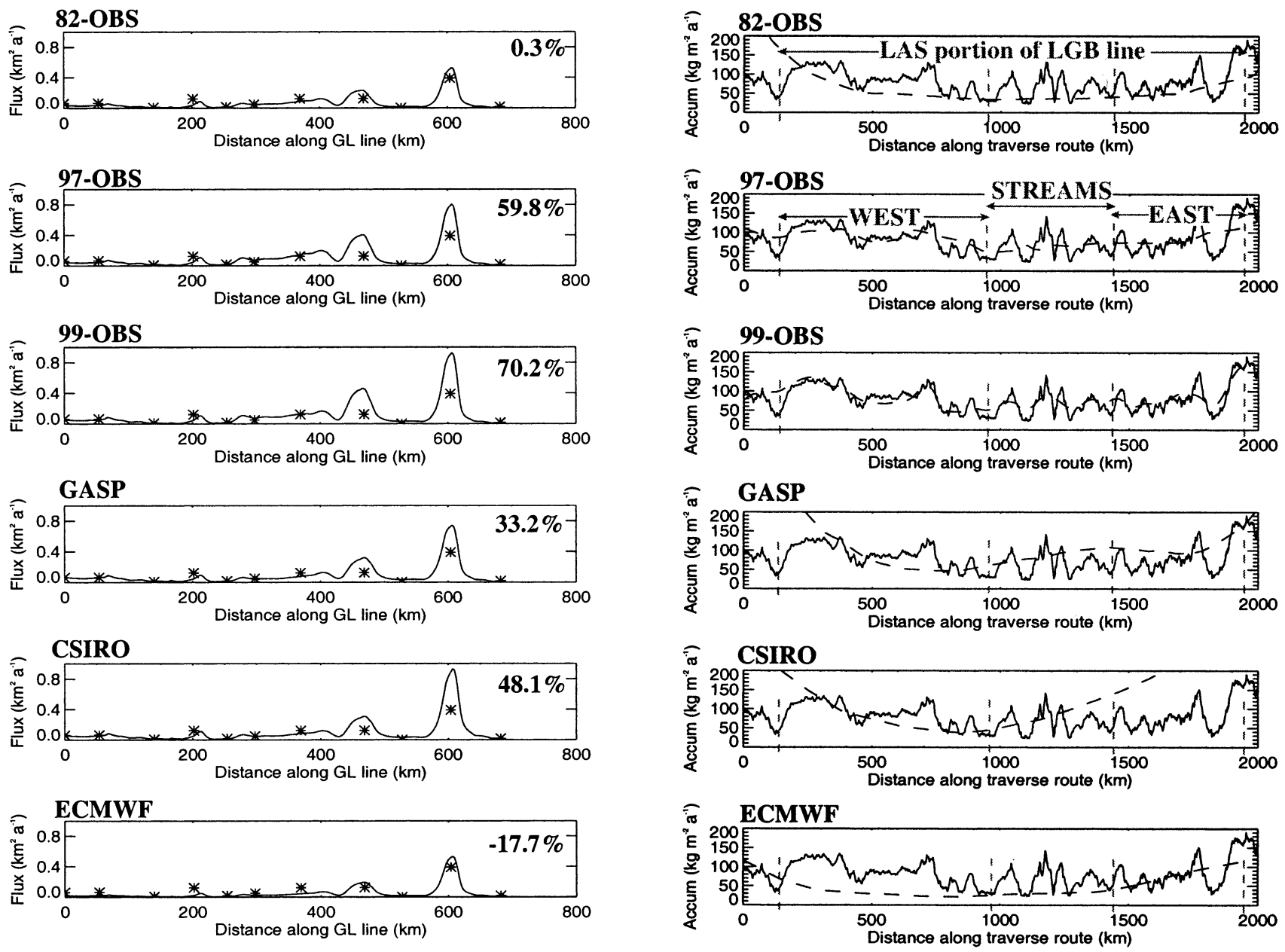

Fig. 5. Profiles of balance fluxes across the perimeter of the $G L$ sites derived for the six accumulation distributions used in this study. For each case the excess of the integrated balance flux above the total observed flux is shown in the top righthand corner, as a percentage of the total observed flux. The flux at each GL site derived from observations is shown as an asterisk, and the total integrated flux is estimated from the GL observations as $33.8 \mathrm{Gta}^{-1}$.

\section{DISGUSSION}

To examine the broad-scale spatial variation in balance fluxes obtained from the different accumulation distributions, the LGB line was divided into three segments: "East", "Streams" and "West" (Fig. 4; second plot). The balance flux across each segment is the integrated accumulation over the catchment for that segment. Spatial differences between the various accumulation distributions are thus reflected in their relative disagreements with the observed fluxes along the LGB line. The relative mass imbalances for each accumulation distribution, and for each sector, are shown in Table 2.

Figure 4 and Table 2 show that there is considerable variability between the six different balance-flux distributions. There are large differences in the overall state of balance, in the percentage imbalances for different segments and in the spatial variation of the balance-flux values. For example, for the 99-OBS distribution, balance-flux values for the East and West segments are quite close to the measured fluxes $(-3.7 \%$ and $+3.8 \%$ ), whereas the values in the Streams segment are not well matched $(+39.3 \%)$. The 97-OBS case is similar, with small negative imbalances for the East and West segments and a stronger positive imbalance $(+19.7 \%)$ for the Streams seg-

Fig. 6. Accumulation measurements made at $2 \mathrm{~km}$ intervals along the LGB traverse route (Higham and Craven, 1997; solid lines) and the interpolated accumulation from each of the accumulation datasets used in this study (dashed lines).

ment. Some of the balance-flux distributions suggest regional thickening of the ice sheet in one segment and regional thinning in the other. For the CSIRO distribution, balance fluxes in the West section are slightly less than the observed fluxes $(-14.1 \%)$, whereas for the East segment the balance fluxes are much higher $(+70.8 \%)$.

For the ECMWF distribution, the balance fluxes are much lower than the observed fluxes in the West segment $(-62.3 \%)$, and also slightly lower in the East segment $(-15.0 \%)$. In fact, the ECMWF accumulation distribution gives a result that is considerably different from all others. The inferred mass balance is negative in each segment, and the total net mass balance $(-34.7 \%)$ is much more negative than any other distribution. This suggests that the ECMWF accumulation distribution underestimates the accumulation over the catchment region. The inferred mass balance for the 82-OBS distribution is also negative in every sector, and more negative in total than for any distribution other than ECMWF.

Comparison of the measured accumulation rates along the LGB traverse route with the coinciding values interpolated from each accumulation distribution (Fig. 6) provides information on the reliability of each accumulation distribution for this part of the basin. It is apparent that the oldest observation-based distribution (82-OBS) underestimates the overall accumulation along the LGB traverse route. The more recent observation-based compilations (97OBS and 99-OBS) include the LGB traverse data, and so follow the observations closely, with small differences intro- 
duced by smoothing effects. The ECMWF accumulation distribution also underestimates the real accumulation, being even lower than 82-OBS for the western side of the basin. The CSIRO accumulation distribution has the largest overestimate of all the distributions (in the East segment), whilst the GASP accumulation distribution appears to slightly overestimate in the East segment and slightly underestimate in the West segment.

The ECMWF and 82-OBS accumulation distributions disagree most with observations around the LGB traverse, and the mass fluxes derived from them lie outside the range of those derived from the other distributions. Eliminating the estimates based on these two distributions narrows the range of estimates in the mass balance to $-16.8 \%$ to $+19.9 \%$, with both of the recent observational accumulation distributions indicating an overall positive balance.

Setting aside uncertainties related to the accuracy of the accumulation distributions, a real disparity in the inferred state of balance for different sectors of the Lambert-Amery system for each distribution could arise for two reasons. Either the different sectors respond at different rates to changes in the accumulation, or the accumulation rates in the three sectors are controlled by different physical processes and do not change uniformly in response to a changing climate. For example, for four of the distributions, the Streams segment has the most positive imbalance. The exceptions are 82-OBS, which has a fairly uniform negative imbalance, and CSIRO, which has an extreme positive imbalance in the East region. The Streams segment is the part of the system that drains through the fast-flowing streams, and it might be expected to respond more quickly to changes in accumulation rate than the East and West segments. However, in this segment, the ice originates from much further inland and is initially very slow-moving, reaching higher velocities only in the ice streams. The overall response time for ice draining from the interior via the ice streams is probably longer than that from the sides of the basin. The different sides of the basin might also respond differently to changing climate because their present-day accumulation rates are different. Allison (1998) showed from accumulation measurements and automatic weather station data that the eastern side of the basin is in a "precipitation shadow" and that present-day accumulation rates there are considerably lower than at sites of equivalent elevation on the western side.

The differences in net balance values derived from the various accumulation distributions reflect a large uncertainty in our knowledge of the "true" accumulation distribution over the Lambert-Amery basin. Even without knowledge of the "true" accumulation, however, there is some indication given here of relative errors in the accumulation in different regions. While it is reasonable that some parts of the basin may be in different states of balance, it is unlikely that the larger regional disparities have a physical origin. Some of the apparent imbalances, such as the $+70.8 \%$ imbalance in the East segment for CSIRO, and the $-62.3 \%$ in the West segment for ECMWF, are undoubtedly due to deficiencies in the respective accumulation distributions and are reflected in the comparisons with the LGB traverse measurements (Fig. 6). However, other apparent imbalances, such as that for the GASP distribution which suggests quite negative balances in the West and East segments, and the differences in the Streams segment between 97-OBS and 99-OBS, are more subtle and are dependent on the accumulation upstream of the LGB traverse route. The balance fluxes thus can give an integrative "probe" of accumulation remote from the point of flux measurement. The largest imbalances are $+70.8 \%$ of CSIRO East, $-62.3 \%$ of ECMWF West and $-48.0 \%$ of GASP East, and these probably highlight regional deficiencies in the source accumulation distributions. For accumulation distributions based on atmospheric models where agreement with, and uncertainties about, the mean accumulation rate for the whole continent are typically $10 \%$ or more, these regional comparisons may be considered severe tests.

For the relatively uniformly flowing ice sheet in the West segment, all distributions suggest a net balance that is either negative or very close to balance (Table 2). In contrast, in the Streams segment, all but the ECMWF distribution and the 82-OBS distribution (both of which are inferior in other respects) show an overall balance that is positive. Regional differences between the six balance-flux distributions are greatest in the East segment. This is the region where in situ accumulation data from the interior are most sparse, which affects the observation-derived distributions. Furthermore, the accumulation is lower here and the flowlines are longer, so this region may be expected to be slower at reaching balance than the West region. This difference in catchment "depth" and the distance to the main glacier and the grounding line may influence the response times.

Further downstream, across the sector of the GL line between 0 and $400 \mathrm{~km}$, the balance fluxes for all of the distributions (except ECMWF) are similar (Fig. 5). The major variation between distributions occurs across Mellor and Lambert Glaciers.

Flowlines calculated using the LAS-DEM show that the ice flowing across the section of the LGB line between LGB12 and LGB56 would eventually flow on through the GL line. The observed flux through this section of the LGB line is calculated from the traverse measurements to be 33.7 $\mathrm{Gta}^{-1}$, which is very close to the estimate of $33.8 \mathrm{Gta}^{-1}$ outflow across the GL line from Allison (1979), as rescaled to the parameters of this study. The four accumulation distributions that gave a positive mass balance in this section of the LGB line (CSIRO, GASP, 99-OBS and 97-OBS) have a much more positive balance here (Fig. 5). The measured inflow across the LGB traverse and the measured outflow across the GL line suggest that the entire accumulation for this region goes into thickening the ice sheet. The integrated accumulation estimates from 97-OBS and 99-OBS, which should be well constrained by observations in this region, are 15 and $13.5 \mathrm{Gt} \mathrm{a}^{-1}$, respectively.

This suggests that the sector of the basin flowing through Streams segment has been in a state of positive mass imbalance over the long period taken to reach the LGB line (tens of thousands of years). Furthermore, the mass balance of the region between the LGB line and GL line has become more positive in the recent past (several thousand years). The region of highest flux across the GL line corresponds to GL10, which was positioned on Lambert Glacier (Allison, 1979). The agreement between the locations of the computed flux maxima and the GL line stations on Fisher, Mellor and Lambert Glaciers indicates that these stations were successfully located close to the centres of those ice streams in Allison's (1979) study. The differences in the flux magnitudes at these maxima reflect the state of imbalance in the streams, although a possible contribution to ice flow from sliding could lead to the surface velocity factor and the observed fluxes being underestimated by several per cent. 
The general agreement between the shapes of the six calculated flux distributions and the fluxes derived from the measurements (Fig. 5) suggests that computed balance-flux distributions can provide a physically motivated interpolation between measured stations. They could thus be used to interpolate between spot flux measurements, with regional rescaling of the balance fluxes to match observations if required, allowing estimates of integrated observed fluxes to be made across sparsely sampled transects.

\section{GONGLUSIONS}

We have examined the state of balance of the LambertAmery system by computing balance fluxes for the system, using a revised version of the scheme described in Budd and Warner (1996), and comparing them with measured fluxes along two lines. To test the sensitivity of the balance-flux distribution to the input accumulation distribution, balance fluxes were computed using six different accumulation distributions combined with a $5 \mathrm{~km}$ DEM generated from ERS-1 satellite-radar altimetry (Fricker and others, 2000). Interpolated balance fluxes and observed fluxes derived from velocity and ice-thickness measurements made in situ were compared at the 73 stations of the LGB traverse and at 11 stations further downstream (the GL line).

For the LGB traverse line, the six estimates for the mass imbalance varied from $-34.7 \%$ to $+19.9 \%$, depending on the accumulation distribution. Elimination of the two outlying accumulation distributions, which were inconsistent with in situ accumulation measurements made along the LGB traverse line, narrowed the range of mass imbalance to $-16.8 \%$ to $+19.9 \%$, with a tendency towards more positive balances. Estimates of imbalances in different regions of the basin differed greatly according to the particular choice of accumulation distribution.

Further downstream, observed and computed fluxes were compared at the eleven GL stations of Allison (1979). Imbalance for this traverse line ranged from $-17.7 \%$ to $+70.2 \%$, where four of the values exceeded $+30 \%$, strongly suggesting that, overall, the portion of the whole basin which drains through this transect is in positive balance. The comparison with the observed fluxes over the corresponding part of the LGB line upstream of the GL line shows that the region between the LGB and GL lines is in positive imbalance. This suggests that the mass balance of the region between the LGB line and the GL line has become more positive in the recent past (several thousand years).

With the availability of detailed mass-flux measurements across two transects, and an accurate DEM for the entire basin, the Lambert-Amery system is now one of the best-studied Antarctic drainage basins in terms of mass balance. However, accumulation rates for the interior are still not well known. Results from this study tentatively suggest that the interior of the LGB is in a state of positive imbalance, and they strongly suggest that the region between 1500 and $2500 \mathrm{~m}$ is in positive imbalance. These results are subject to large uncertainties in the distribution of accumulation over the basin.

Our study has reconfirmed the importance of accurate estimates of accumulation for mass-balance studies. The results suggest that the current estimates of Antarctic accumulation rates are inadequate for this type of study, and this is the most significant gap in current mass-balance estimates. We con- clude that before an accurate mass-balance computation can be made for Antarctica, further work is needed to improve accumulation estimates over large regions of the ice sheet.

\section{ACKNOWLEDGEMENTS}

The field data used in this paper were gathered by the many people who participated in or supported the ANARE LGB traverses between 1989/90 and 1994/95. Special thanks, from among these, are due to R. Kiernan, M. Higham, A. Brocklesby and M. Craven. We also thank M. Craven for producing the map in Figure 1. Finally, we thank P. Reid for helping us with access to the GASP, CSIRO and ECMWF datasets.

\section{REFERENGES}

Allison, I. 1979. The mass budget of the Lambert Glacier drainage basin, Antarctica. 7. Glaciol., 22(87), 223-235.

Allison, I. 1998. Surface climate of the interior of the Lambert Glacier basin, Antarctica, from automatic weather station data. Ann. Glaciol., 27, 515-520.

Bentley, C. R. and M. B. Giovinetto. 1991. Mass balance of Antarctica and sea level change. InWeller, G., C. L. Wilson and B. A. B. Severin, eds. International Conference on the Role of the Polar Regions in Global Change: proceedings of a conference held June 11-15, 1990 at the University of Alask a Fairbanks. Vol. II. Fairbanks, AK, University of Alaska. Geophysical Institute/Center for Global Change and Arctic System Research, 481-488.

Budd, W. 1968. The longitudinal velocity profile of large ice masses. International Association of Scientific Hydrology Publication 79 (General Assembly of Bern 1967 Snow and Ice), 58-77.

Budd, W. F. and I. N. Smith. 1982. Large-scale numerical modelling of the Antarctic ice sheet. Ann. Glaciol., 3, 42-49.

Budd, W. F. and R. C. Warner. 1996. A computer scheme for rapid calculations of balance-flux distributions. Ann. Glaciol., 23, 21-27.

Budd, W. F., D. Jenssen and U. Radok. 1971. Derived physical characteristics of the Antarctic ice sheet. ANARE Interim Rep., Ser. A(IV), Glaciol. 120. (Meteorology Dept. Publ. 18.)

Budd, W. F., M. J. Corry and T. H. Jacka. 1982. Results from the Amery Ice Shelf Project. Ann. Glaciol., 3, 36-41.

Budd, W. F., P. A. Reid and L. J. Minty. 1995. Antarctic moisture flux and net accumulation from global atmospheric analyses. Ann. Glaciol., 21, 149-156.

Craven, M., M. Higham and A. Brocklesby. In press. Ice thicknesses and surface and bedrock elevations from the Lambert Glacier basin traverses 1990-95. Hobart, Tasmania, Antarctic CRC. (Research Report.)

Drewry, D. J., S. R. Jordan and E. Jankowski. 1982. Measured properties of the Antarctic ice sheet: surface configuration, ice thickness, volume and bedrock characteristics. Ann. Glaciol., 3, 83-91.

European Centre for Medium-range Weather Forecasts (ECMWF). 1997. The description of the ECMWF re-analysis global atmospheric data archive. Reading, European Centre for Medium-range Weather Forecasts.

Fricker, H. A., G. Hyland, R. Coleman and N.W. Young. 2000. Digital elevation models for the Lambert Glacier-Amery Ice Shelf system, East Antarctica, from ERS-1 satellite-radar altimetry. F. Glaciol., 46(155), 553-560.

Giovinetto, M. B. and C. R. Bentley. 1985. Surface balance in ice drainage systems of Antarctica. Antarct. F. U.S., 20(4), 6-13.

Hamley, T. C., I. N. Smith and N.W. Young. 1985. Mass-balance and iceflow-law parameters for East Antarctica. 7. Glaciol., 31 (109), 334-339. Erratum: 32(112), 1986, p. 550.

Higham, M. and M. Craven. 1997. Surface mass balance and snow surface properties from the Lambert Glacier basin traverses 1990-94. Hobart, Tasmania, Cooperative Research Centre for the Antarctic and Southern Ocean Environment. (Research Report 9.)

Higham, M., M. Reynolds, A. Brocklesby and I. Allison. 1995. Ice radar digital recording, data processing and results from the Lambert Glacier basin traverses. Terra Antartica, 2(1), 23-32.

Higham, M., M. Craven, A. Ruddell and I. Allison. 1997. Snow-accumulation distribution in the interior of the Lambert Glacier basin, Antarctica. Ann. Glaciol., 25, 412-417.

Jacobs, S. S., H. H. Hellmer, C. S. M. Doake, A. Jenkins and R. M. Frolich. 1992. Melting of ice shelves and the mass balance of Antarctica. F. Glaciol., 38(130), 375-387.

Kiernan, R. In press. Ice sheet surface velocities along the Lambert Glacier basin traverse route. Hobart, Tasmania, Antarctic CRC. (Research Report 10.)

McIntyre, N. F. 1985. A re-assessment of the mass balance of the Lambert 
Glacier drainage basin, Antarctica. 7. Glaciol., 31(107), 34-38. Erratum: 31 (109), p. 383.

Meier, M. F. 1993. Ice, climate, and sea level: do we know what is happening? In Peltier, W. R., ed. Ice in the climate system. Berlin, etc., Springer-Verlag, 141-160. (NATO ASI Series I: Global Environmental Change 12.)

Morgan, V. I. and W. F. Budd. 1975. Radio-echo sounding of the Lambert Glacier basin. F. Glaciol., 15(73), 103-111.

Phillips, H. A. 1999. Applications of ERS satellite radar altimetry in the Lambert Glacier-Amery Ice Shelf system, East Antarctica. (Ph.D. thesis, University of Tasmania.)

Shimizu, H., O. Watanabe, S. Kobayashi, T. Yamada, R. Naruse and Y.
Ageta. 1978. Glaciological aspects and mass budget of the ice sheet in Mizuho Plateau. Natl. Inst. Polar Res. Mem., Special Issue 7, 264-274.

Smith, I. N., W. F. Budd and P. Reid. 1998. Model estimates of Antarctic accumulation rates and their relationship to temperature changes. Ann. Glaciol., 27, 246-250.

Vaughan, D. G., J. L. Bamber, M. B. Giovinetto, J. Russell and A. P. R. Cooper. 1999. Reassessment of net surface mass balance in Antarctica. 7. Climate, $12(4), 933-946$.

Whillans, I. M. and R. A. Bindschadler. 1988. Mass balance of Ice Stream B, West Antarctica. Ann. Glaciol., 11, 187-193.

MS received 13 August 1999 and accepted in revised form 26 June 2000 